\title{
ORIGINAL
}

ARTICLES

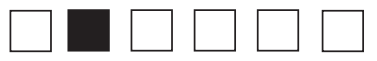

\section{Coding Family Medicine Residency Clinic Visits, 99213 or 99214 ? A Residency Research Network of Texas Study}

Richard A. Young, MD; Sarah Holder, DO; Neelima Kale, MD; Sandra K. Burge, PhD; Kaparaboyna A. Kumar, MD

BACKGROUND AND OBJECTIVES: The purpose of this study was to characterize Current Procedural Terminology (CPT) coding patterns for professional services in family physician (FP) residency clinics.

METHODS: Trained assistants directly observed during every other FP-patient encounter in 10 clinics affiliated with eight residencies of the Residency Research Network of Texas. Three investigators later independently coded each visit for the highest code level reasonably allowed. The primary outcome was the number of clinic visits that were actually coded as a CPT 99203/213 that could have been coded at a higher level.

RESULTS: In 850 physician-patient encounters where the CPT code billed was identified, the investigators completely agreed on the allowable code $93 \%$ of the time. Overall, a 99203/13 or lower or preventive services code was billed in 651 visits (76.6\%), more commonly in resident visits (515/570 [90.4\%] vs $136 / 280$ for faculty [48.6\%], $P<.001)$. There were $476 / 660$ (72.1\%) visits coded at a 99213 or less that could have been coded as a $99204 / 214$ or higher. This was more common in resident visits 385/434 (88.7\%), but there was undercoding in faculty patients as well $91 / 226$ (40.3\%). We found very few cases of overcoding-16 total.

CONCLUSIONS AND RELEVANCE: FPs coding patient encounters in residency clinics undercode for their work, which leads to decreased clinic revenue. This may be because the primary care exception is felt to be too onerous to bill for higher-paid codes, or a lack of knowledge of CMS coding rules among residents and faculty, or other reasons.

(Fam Med. 2019;51(6):477-82.)

doi: 10.22454/FamMed.2019.862757

Published Online First April 23, 2019

n 1995 and 1997, the Centers for Medicare and Medicaid Services (CMS) published guidelines for documentation, coding, and billing for evaluation and management (E\&M) services provided to its beneficiaries that are still used today. ${ }^{1,2}$

The most common Current Procedural Terminology (CPT) codes used by family physicians (FPs) are 99213 and $99214 .^{3}$ Under the $1997 \mathrm{E \& M}$ rules and CPT Appendix C examples, a 99213 can be billed if a physician sees a patient for one stable chronic disease (eg, stable cirrhosis of the liver). ${ }^{4} \mathrm{~A} 99214$ can be billed if an FP cares for a patient with one chronic disease not in optimal control (eg, stable angina, 2 months postmyocardial infarction, who is not tolerating one of his medications). ${ }^{4}$ This issue is important because previous observational studies of FPs' clinic work found that they actually manage a mean of 2.5 to 3.1 diagnoses in the average clinic visit, ${ }^{5-7} 3.9$ to 6 for elderly patients, and 4.6 for patients with diabetes. ${ }^{6,8}$

CMS is by far the biggest payer of the cost of graduate medical education (GME). It generally requires that the attending physician perform the key elements of a patient encounter to appropriately bill CMS for the clinic service in a residency environment. However, CMS allows an exception for evaluation and management (E\&M) services furnished in certain primary care centers. ${ }^{9}$ The most common practical impact is that a resident can see a CMScovered patient and bill a 99203/213 without the attending having to independently perform and document key elements of the E\&M visit. Previous research in Washington state found that the higher E\&M codes, 99204-5/99214-5, were infrequently

From JPS Family Medicine Residency Program, Fort Worth, TX (Dr Young); AtlantiCare Family Medicine Residency Program, Atlantic City, NJ (Dr Holder); University of Texas Southwestern Medical School Department of Family Medicine (Dr Kale); and University of Texas Health Science Center at San Antonio, Department of Family and Community Medicine (Drs Burge and Kumar). 
billed in family medicine residency clinics. ${ }^{10}$ We speculated that the primary care exception billing rules were a contributing factor to this finding.

The purpose of our study was to compare the actual CPT codes billed in clinics associated with family medicine residencies to codes that reasonably could have been billed.

\section{Methods}

This was a cross-sectional observational study of primary care visits in 10 clinics of eight family medicine residencies that are members of the Residency Research Network of Texas (RRNeT). A full description of the basic methods has been published previously. ${ }^{11}$ Trained observers directly observed family physician-patient encounters and recorded data mostly based on the instruments used by the National Ambulatory Medical Care Survey. These included items such as the number of concerns the patient raised, the number of issues the physician addressed, the number of labs, images, referrals, and prescriptions ordered in the encounter, and the actual CPT code billed by the physician. The observers were medical students who had no previous training or experience in CPT coding or CMS documentation rules. Therefore, we did not ask them to review each note for documentation details such as review of system bullet points. The primary aim of the overall study was the time-motion aspect. Observers were instructed to not ask the physician to take more than a few seconds to report the CPT code that was intended to be billed, even if it meant not capturing the CPT code for that visit.

According to the CPT manual, Preventive Medicine Services codes (commonly referred to as well person codes, 99391, 99392, etc) are a subsection of the E\&M codes. The more-often used 99213/99214 codes are called Office or Other Outpatient Services codes, but are still a subsection of the E\&M section. The primary aim of our analysis was to inquire about CPT coding, regardless of the nature of the clinic encounter. None of the residency sites used EMR tools to help select the CPT code for their clinic encounters.

\section{Data Coding}

Three of the investigators (R.Y., S.H., N.K.) independently reviewed the data for each encounter and determined if a visit could reasonably be coded as 99213, 99214, etc, on based on CPT coding rules. The investigators have 25,10 , and 19 years of clinical experience, respectively. None are certified coders.

Collected data did not include the documentation of the progress note for each visit, so factors inherent in the CMS documentation rules, such as how many physical exam bullet points were documented, were not measured. ${ }^{1}$ Encounters where all three investigators concurred were deemed as finally classified. All others were reexamined by each investigator so each could comment on why he or she felt a certain code was reasonable. Whichever code was finally chosen by at least a two-thirds majority was deemed the final code used in the analysis. The primary outcome was the number of clinic visits that were actually coded as a CPT 99203/213 that could have been coded at a higher level. Subanalyses included differences by faculty, training year, location, patient characteristics, and physician characteristics.

\section{Data Analysis}

Results were analyzed using descriptive statistics. Group comparisons of continuous variables were assessed using independent samples $t$-tests or ANOVA as appropriate, and comparisons of all categorical data were analyzed using $\chi^{2}$. SPSS version 20 was used for analysis (SPSS Inc, Chicago, IL). All tests were two-tailed and a levels were set at 0.05 to determine statistical significance.

The Institutional Review Board (IRB) of the University of Texas Health Science Center at San Antonio and the individual residencies' IRBs (where required) approved this study.

\section{Results}

Nine hundred eighty-two physicianpatient ambulatory visits were observed and recorded. Of these, 850 captured the actual E\&M code initially submitted by the physician, whether it was an Office or Other Outpatient code or a Preventive Services code (six visits where only a $G$ code was billed were not included). Table 1 shows patient and physician characteristics. The majority of patients were white/Hispanic (54.1\%), female $(61.4 \%)$, and with a mean age of 45.8 years, ranging from newborns to elders age 90 years and above. Faculty patients tended to be older and have more chronic diseases.

In 850 physician-patient encounters where the actual CPT code billed was identified, the investigators completely agreed on the allowable code $93 \%$ of the time. In the other $7 \%$, the majority determined whether the code could be billed at a 99214 or higher.

Overall, a 99203/13 or lower or a preventive services code was billed in 651 visits (76.6\%), more commonly in resident visits (515/570 [90.4\%] vs $136 / 280$ for faculty [48.6\%], $P<.001$; Table 2). There were $476 / 660$ $(72.1 \%)$ visits coded at a 99213 or less that could have been coded as a 99204/214 or higher. This was more common in resident visits $(385 / 434$ [88.7\%]), but there was undercoding in faculty patients as well (91/226 [40.3\%]). We found very few cases of overcoding - 16 total. There was no difference between residents and faculty on the proportion of visits where only a preventive services code was billed (42/570 [7.4\%] for residents, 26/254 [9.3\%] for faculty, $P=0.33$ )

The number of visits billed as a 99203/13 or lower that could have been billed as a 99204/14 or higher increased by training year (PGY-1: 5/8 [62.5\%]; PGY-2: 161/205 [78.5\%]; PGY-3: 250/295 [84.7\%]; PGY-4: 16/16 [100.0\%]; Faculty 106/135 [78.5\%]; $P=.047$ ). More issues were addressed in the faculty visits than the resident clinics ( 4.1 for faculty vs 3.4 for residents, $P<.001)$. There was a difference in the number of visits 
Table 1: Patient and Physician Characteristics

\begin{tabular}{|c|c|c|c|c|}
\hline \multicolumn{5}{|c|}{ Patients } \\
\hline Characteristic & Faculty Patients $n=\mathbf{2 8 0}$ & $\begin{array}{c}\text { Resident Patients } \\
n=570\end{array}$ & $\begin{array}{l}\text { Overall } \\
N=850\end{array}$ & $P$ Value \\
\hline Age, mean (SD) & $51.4(20.7)$ & $42.9(22.8)$ & $45.8(22.4)$ & $<.001$ \\
\hline \multicolumn{5}{|c|}{ Race/Ethnicity; n (\%) } \\
\hline Hispanic & $110(39.3)$ & $349(60.7)$ & $459(54.1)$ & $<.001$ \\
\hline White & $101(36.1)$ & $92(16.2)$ & $193(22.7)$ & $<.001$ \\
\hline Black & $48(17.1)$ & $115(20.2)$ & $163(19.2)$ & .29 \\
\hline Asian & $19(6.8)$ & $16(2.8)$ & $35(4.1)$ & .006 \\
\hline Female, n (\%) & $168(60.0)$ & $353(62.0)$ & $521(61.4)$ & .57 \\
\hline BMI, mean (SD) & $31.3(8.2)$ & $31.4(8.0)$ & $31.4(8.0)$ & .77 \\
\hline Diastolic BP, mm Hg (SD) & $73.6(10.9)$ & $74.0(12.0)$ & $73.9(11.6)$ & .62 \\
\hline Systolic BP, mm HG (SD) & $126.0(18.7)$ & $126.8(30.0)$ & $126.5(20.2)$ & .62 \\
\hline \multicolumn{5}{|c|}{ Chronic Diseases; n (\%) } \\
\hline Hypertension & $137(48.7)$ & $219(38.4)$ & $358(42.9)$ & .005 \\
\hline Diabetes & $82(29.0)$ & $160(28.1)$ & $242(28.5)$ & .79 \\
\hline Hyperlipidemia & $91(32.5)$ & $135(23.6)$ & $226(26.6)$ & .016 \\
\hline Depression & $63(22.5)$ & $85(14.8)$ & $147(17.3)$ & .005 \\
\hline Arthritis & $53(19.0)$ & $64(11.2)$ & $117(13.8)$ & .002 \\
\hline Anxiety & $51(18.2)$ & $45(7.8)$ & $96(11.3)$ & $<.001$ \\
\hline Asthma & $40(14.3)$ & $34(6.0)$ & $74(8.7)$ & $<.001$ \\
\hline Coronary artery disease & $18(6.5)$ & $24(4.2)$ & $42(5.0)$ & .16 \\
\hline \multicolumn{5}{|c|}{ Physicians (Number of Visits With Physicians Fitting the Description) } \\
\hline & Faculty & Residents & Overall & \\
\hline Years clinical experience (SD) & $16.6(10.2)$ & $2.6(.6)$ & $7.1(8.5)$ & $<.001$ \\
\hline \multicolumn{5}{|c|}{ Race/Ethnicity; n (\%) } \\
\hline Hispanic & $54(19.3)$ & $218(38.3)$ & $272(32.0)$ & $<.001$ \\
\hline White & $78(27.9)$ & $233(40.9)$ & $311(36.6)$ & $<.001$ \\
\hline Black & $12(2.1)$ & $17(6.1)$ & $29(3.4)$ & .003 \\
\hline Asian & $105(37.5)$ & 95 (16.7) & $200(23.6)$ & $<.001$ \\
\hline Female, n (\%) & $147(52.5)$ & $281(49.4)$ & $428(50.4)$ & .39 \\
\hline $\begin{array}{l}\text { Number of issues addressed in the clinic } \\
\text { visit; number (\%) }\end{array}$ & $4.1(2.4)$ & $3.4(1.9)$ & $3.6(2.1)$ & $<.001$ \\
\hline
\end{tabular}

that could be billed higher than a $99203 / 13$ by clinic site $(P<.001$, Table $1)$. If the preventive services visits are removed from the analysis, there are no appreciable changes our findings (Table 1).

Table 3 shows the results if the visits are limited to the 173 patients ages 65 and above (used as a proxy for Medicare as the payer). Faculty were more likely to bill a 99214 or higher than residents (29/75 [38.7\%] vs $16 / 98$ [16.3\%], $P=.001)$. The faculty and resident patients were more similar in the number of issues that were addressed in the clinic (4.2 vs $3.7, P=.17)$ and the number of visits that could have been billed as a 99214 were essentially identical $(88.0 \%$ vs $87.8 \%)$.

\section{Discussion}

In this study of 850 FP-patient ambulatory visits in residency clinics, FPs were found to significantly undercode their clinical work, which occurred in most resident visits, but also in faculty visits. The resident undercoding increased each training year.

Our results are similar to the billing patterns reported by CawseLucas, et al, in family medicine residencies in the Pacific Northwest, who found a CPT code of 99213 or lower was charged in $74.9 \%$ to $86.7 \%$ of visits, ${ }^{10}$ a rate similar to ours $(76.6 \%)$. Cawse-Lucas, et al's percentage of attending physician 
Table 2: Current Procedural Terminology (CPT) Code Results

\begin{tabular}{|c|c|c|c|c|}
\hline Characteristic & $\begin{array}{l}\begin{array}{l}\text { Faculty Patients } \\
\mathbf{n}=\mathbf{2 8 0}\end{array}\end{array}$ & $\begin{array}{l}\begin{array}{l}\text { Resident Patients } \\
n=570\end{array}\end{array}$ & Overall $\mathbf{N}=\mathbf{8 5 0}$ & $P$ Value \\
\hline \multicolumn{5}{|c|}{ CPT Codes Actually Billed; Number (\%) } \\
\hline $99203 / 213$ or lower or preventive services code* & $136(48.6)$ & $515(90.4)$ & $651(76.6)$ & \multirow{2}{*}{$<.001$} \\
\hline 99204/214 or higher code & $144(51.4)$ & $55(9.6)$ & $199(23.4)$ & \\
\hline \multicolumn{5}{|c|}{ Highest Complexity Level CPT Codes as Determined by the Investigators; Number (\%) } \\
\hline $\begin{array}{l}\text { Coded as a } 99203 / 213 \text { or less or preventive services } \\
\text { code }\end{array}$ & $54(19.3)$ & $136(23.9)$ & $190(22.4)$ & \multirow[t]{2}{*}{.18} \\
\hline Coded as a $99204 / 214$ or higher & $226(80.7)$ & $434(76.1)$ & $660(77.6)$ & \\
\hline \multicolumn{5}{|c|}{ Breakdown of Visits Where a 99204/214 or Higher CPT Code Was Appropriate; Number (\%) } \\
\hline $\begin{array}{l}\text { Coded as a } 99203 / 213 \text { or less (\% of those visits } \\
\text { where the higher code was appropriate) }\end{array}$ & $91(40.3)$ & $385(88.7)$ & $476(72.1)$ & \multirow{2}{*}{$<.001$} \\
\hline $\begin{array}{l}\text { Coded as a } 99204 / 214 \text { or higher (\% of those visits } \\
\text { where the higher code was appropriate) }\end{array}$ & $135(59.7)$ & $49(11.3)$ & $184(27.9)$ & \\
\hline
\end{tabular}

*99381-7/99391-7 Preventive Services Codes under the CPT Evaluation and Management codes.

Table 3: Current Procedural Terminology (CPT) Code Results for Patients 65 and Older

\begin{tabular}{|c|c|c|c|c|}
\hline Characteristic & Faculty Patients, n=75 & Resident Patients, $\mathrm{n}=98$ & Overall, $\mathrm{N}=\mathbf{1 7 3}$ & $P$ Value \\
\hline \multicolumn{5}{|c|}{ CPT Codes Actually Billed, Number (\%) } \\
\hline $99203 / 213$ or lower or well person code* & $46(61.3)$ & $82(83.7)$ & $128(74.0)$ & \multirow{2}{*}{.001} \\
\hline 99204/214 or higher code & $29(38.7)$ & $16(16.3)$ & $45(26.0)$ & \\
\hline \multicolumn{5}{|c|}{ 99204/214 or Higher CPT Code Is Appropriate, Number (\%) } \\
\hline Coded as a $99203 / 213$ or less & $22(33.3)$ & $72(83.7)$ & $94(61.2)$ & \multirow{2}{*}{$<.001$} \\
\hline Coded as a $99204 / 214$ or higher & $44(66.7)$ & $14(16.3)$ & $58(38.8)$ & \\
\hline \multicolumn{5}{|c|}{ Potential CPT Codes, Number (\%) } \\
\hline $\begin{array}{l}\text { Coded as a } 99203 / 213 \text { or less or well } \\
\text { person code }\end{array}$ & $9(12.0)$ & $12(12.2)$ & $21(12.1)$ & \multirow[t]{2}{*}{.96} \\
\hline Coded as a $99204 / 214$ or higher & $66(88.0)$ & $86(87.8)$ & $152(87.9)$ & \\
\hline $\begin{array}{l}\text { Number of issues addressed in the clinic } \\
\text { visit, number }(\%)\end{array}$ & $4.2(2.1)$ & $3.7(2.2)$ & $4.0(2.1)$ & .17 \\
\hline
\end{tabular}

*99381-7/99391-7 Preventive Services Codes under the CPT Evaluation and Management codes.

clinic visits billed for Medicare patients as a 99214 or higher $(34.2 \%$ to $39.7 \%$ ) was also similar to ours $(33.3 \%)$. Their study made no attempt to judge the appropriateness of the CPT code that was billed for each visit, which was a strength of our study. Our results assume age 65 years and older is a reasonable proxy for Medicare patients. Resident clinics in the Northwest (where the primary care exception was only applied to Medicare patients) were more likely to use the higher codes ( $25.2 \%$ vs $16.3 \%$ in our study). This might be partly explained by the Texas clinics having a higher number of patients 65 years or older who are undocumented or otherwise ineligible for Medicare. The lower charges may reflect an effort on the part of the physicians to lower the bill for this vulnerable population.

Our finding that the percentage of patient encounters eligible for a 99204/14 code or higher that was not coded as such increased by training year is intuitive. The number of visits per clinic session increases each training year, which in turn increases the time pressure on a more experienced resident to not check out the patient with the supervising clinic faculty. This may also reflect growing confidence in residents that they don't need the faculty's input in as many clinic encounters. In these cases, under the CMS teaching clinic 
exception rules, the visit can be coded no higher than a 99203/13.

\section{Limitations}

Our study was limited by its observational nature. Observers were mostly consistent in their classification of observed visits, but visits were not audio recorded to cross check the observations as other studies have done. ${ }^{5}$

The actual CPT code billed was not identified in 124 of the visits (11 visits just billed procedure CPT codes or $\mathrm{G}$ codes). We were unable to ascertain if any of the reported codes were changed prior to claim submission to the payer, either during attending review in clinic or later in the billing process after review by support staff. We also did not ask specifically how each clinic applies the primary care exception, only Medicare patients or all patients. Our study has the strength of recording more issues addressed compared to previous research using NAMCS data and not relying on electronic medical records or billing records, which have been shown in previous studies to undercount the number of issues addressed. ${ }^{6}$

The analysis of determining the appropriate CPT code was made difficult by the vague and sometimes conflicting guidance and examples listed in the CPT manual, possibly leading to interobserver variability bias. We attempted to minimize this by completing several rounds of data vetting between three of the investigators (R.Y., S.H., N.K.). There was generally good agreement between the three investigators, more so than reported by studies of professional coders. ${ }^{12-14}$

Finally, we have no way of ascertaining why visits were undercoded. Possible reasons are a lack of knowledge, to avoid extra effort required of higher-level visits (with residents), or an effort to mitigate costs for under- and uninsured patients. Based on the number of undercoded patient encounters by faculty, misunderstandings of eligible codes, a lack of required documentation in the medical record, and coding habit inertia may all be contributing factors.

\section{Implications}

The CMS E\&M guidelines have been recognized as being "fatally flawed" since they were first published in the mid-1990 $\mathrm{s}^{15}$ and this was borne out in subsequent research of the opinions of family physicians, ${ }^{16}$ who complained that the documentation and billing rules are cumbersome and add little to the quality of care delivered. The fact that faculty also undercode implies that there is a culture of coding patterns emergent in residency clinics that does not match national coding patterns in nonteaching offices, ${ }^{17}$ and is an expression of the complexity of the existing rules that the faculty may not fully understand. Another possible contributor to our findings may be that academic family physicians may be motivated more by their role as teachers and less by income generated from direct patient care.

The primary care exception adds an extra layer of difficulty when residents are involved and leads to a pressure to down code. The fact that the resident visits are vastly undercoded compared to faculty visits implies that the primary care exception rule by itself is perceived as a significant barrier to fully allowable CPT coding in family medicine residency clinics. This finding has significant financial implications, ${ }^{10}$ and compounds the problem for the financial survival of family medicine residencies in that family physicians do more cognitive work than can be captured by the existing CPT codes in approximately $60 \%$ of clinic visits. $^{18}$

Our findings suggest that residencies are not being funded as much by patient care revenue as they could be, even just using the existing CPT codes and rules. The Washington study estimated that the revenue loss from undercoding was $\$ 2,559$ per resident and $\$ 57,570$ per faculty per year. ${ }^{10}$ Our findings also suggest that recent residency graduates may take poor coding practices into their early clinical life. Just as the clinical care taught in residency training has a legacy effect on graduates ${ }^{19}$ we assume the coding taught does also. Our findings should remind FM residency faculty of the importance of teaching appropriate coding in residency, as it may impact the graduates significantly (undercoding may encourage a volume mentality rather than providing the appropriate level of care to a reasonable volume of patients during a clinic session). We also acknowledge that the task of teaching proper coding is made more difficult by the fact that the rules are different in teaching vs nonteaching clinics.

These realities also help explain why the Direct Primary Care (DPC) movement is the fastest growing segment of family physicians..$^{20}$ Part of the reported joy of a DPC practice is that the family physician is able to spend more time with patients and is paid (through monthly fees) to also care and communicate by phone calls, emails, and text messages. ${ }^{21-23}$ This means that these practices have been freed from the burdens of CPT codes and CMS E\&M documentation and billing rules. Given the growth of DPC practices and other possible novel documentation, coding, and billing models, CMS should develop GME payment approaches that are not connected to the CPT codes and it should revise its E\&M rules to allow residency clinics to more completely bill for their clinical work.

ACKNOWLEDGMENTS: RRNeT investigators include Nina Torkelson, Jerry Kizerian, Ronya Green, David Edwards, Sunand Kallumadanda, and Tamara Armstrong. The authors thank the medical student research volunteers: Tanner Campbell, Jade Law, Brenda Chavez, Clayton Bishop, Caroline Stephens, Nicholas Inman, Katie Molina, Tiffany Brown, Shannon Brougher, and Thomas Heydon.

FUNDING STATEMENT: This project was funded with the help of the Texas Academy of Family Physicians Foundation. The project described was also supported by the National Center for Advancing Translational Sciences, National Institutes of Health, through Grant UL1 TR002645. The content is solely the responsibility of the authors and does not necessarily represent the official views of the NIH. 
CONFLICTS OF INTEREST: Dr Young discloses that he is the sole owner of SENTIRE, LLC, which is a novel documentation, coding, and billing system for primary care. All other authors report no conflicts.

CORRESPONDING AUTHOR: Address correspondence to Dr Richard A. Young, Director of Research, JPS Family Medicine Residency Program, 1500 S. Main, Fort Worth, TX 76104. 817-702-1241. Fax: 817-702-1691. ryoung01@jpshealth.org.

\section{References}

1. Centers for Medicare and Medicaid Services. 1997 Documentation Guidelines for Evaluation and Management Services. http://www.cms. hhs.gov/MLNProducts/Downloads/MASTER1. pdf. Accessed March 11, 2019.

2. Centers for Medicare and Medicaid Services. Evaluation and Management Services Guide. https://www.cms.gov/Outreach-and-Education/ Medicare-Learning-Network-MLN/MLNProducts/Downloads/eval-mgmt-serv-guideICN006764.pdf. Accessed April 26, 2016.

3. State of Vermont Department of Banking Insurance, Securities, and Health Care Administration. 2009 Provider Reimbursement Report: Primary Care Services. http://www.leg.state. vt.us/reports/2010ExternalReports/251708.pdf. Accessed March 3, 2016.

4. American Medical Association. CPT 2014 Standard Edition. Current Procedural Terminology. Chicago, IL: American Medical Association; 2014.

5. Stange KC, Zyzanski SJ, Jaén CR, et al. Illuminating the 'black box'. A description of 4454 patient visits to 138 family physicians. J Fam Pract. 1998;46(5):377-389.

6. Beasley JW, Hankey TH, Erickson R, et al. How many problems do family physicians manage at each encounter? A WReN study. Ann Fam Med. 2004;2(5):405-410.
7. Flocke SA, Frank SH, Wenger DA. Addressing multiple problems in the family practice office visit. J Fam Pract. 2001;50(3):211-216.

8. Tai-Seale M, McGuire TG, Zhang W. Time allocation in primary care office visits. Health Serv Res. 2007;42(5):1871-1894.

9. Center for Medicare and Medicaid Services. Guidelines for Teaching Physicians, Interns, and Residents. March 2017. https://www.cms. gov/Outreach-and-Education/Medicare-Learning-Network-MLN/MLNProducts/Downloads/ Teaching-Physicians-Fact-Sheet-ICN006437. pdf. Accessed July 7, 2017.

10. Cawse-Lucas J, Evans DV, Ruiz DR, et al. Impact of the Primary Care Exception on Family Medicine Resident Coding. Fam Med. 2016;48(3):175-179

11. Young RA, Burge SK, Kumar KA, Wilson JM, Ortiz DF. A time-motion study of primary care physicians' work in the electronic health record era. Fam Med. 2018;50(2):91-99.

12. Zuber TJ, Rhody CE, Muday TA, et al; Health Care Financing Administration. Variability in code selection using the 1995 and 1998 HCFA documentation guidelines for office services. $J$ Fam Pract. 2000;49(7):642-645.

13. King MS, Sharp L, Lipsky MS. Accuracy of CPT evaluation and management coding by family physicians. J Am Board Fam Pract. 2001;14(3):184-192.

14. King MS, Lipsky MS, Sharp L. Expert agreement in Current Procedural Terminology evaluation and management coding. Arch Intern Med. 2002;162(3):316-320.

15. Kassirer JP, Angell M. Evaluation and management guidelines-fatally flawed. N Engl J Med. 1998;339(23):1697-1698.

16. Young RA, Bayles B, Hill JH, Kumar KA, Burge S. Family physicians' opinions on the primary care documentation, coding, and billing system: a qualitative study from the residency research network of Texas. Fam Med. 2014;46(5):378-384
17. Evans DV, Cawse-Lucas J, Ruiz DR, Allcut EA, Andrilla $\mathrm{CH}$, Norris T. Family medicine resident billing and lost revenue: a regional cross-sectional study. Fam Med. 2015;47(3):175181.

18. Young RA, Burge S, Kumar KA, Wilson J. The Full Scope of Family Physicians' Work Is Not Reflected by Current Procedural Terminology Codes. J Am Board Fam Med. 2017;30(6):724732

19. Chen C, Petterson S, Phillips R, Bazemore A, Mullan F. Spending patterns in region of residency training and subsequent expenditures for care provided by practicing physicians for Medicare beneficiaries. JAMA. 2014;312(22):2385-2393.

20. Eskew PM, Klink K. Direct Primary Care: Practice Distribution and Cost Across the Nation. J Am Board Fam Med. 2015;28(6):793801.

21. Eskew P. In Defense of Direct Primary Care. Fam Pract Manag. 2016;23(5):12-14.

22. Dalen JE, Alpert JS. Concierge Medicine Is Here and Growing!! Am J Med. 2017;130(8):880-881

23. Wu WN, Bliss G, Bliss EB, Green LA. Practice profile. A direct primary care medical home: the Qliance experience. Health Aff (Millwood). 2010;29(5):959-962. 